\title{
REVIEWS
}

\section{The Impact of Combinations of Non-Steroidal Anti-Inflammatory Drugs and Anti-Hypertensive Agents on Blood Pressure*}

\author{
${ }^{1}$ Department of Social and Clinical Pharmacy, Faculty of Pharmacy in Hradec Kralove, Charles University \\ in Prague, The Czech Republic \\ ${ }^{2}$ Sub-Department of Gerontology, Faculty of Medicine in Hradec Kralove, Charles University in Prague, \\ The Czech Republic \\ ${ }^{3} 3^{\text {rd }}$ Clinic of Internal Medicine, Metabolism and Gerontology, University Hospital Hradec Kralove, \\ The Czech Republic
}

A - research concept and design; B - collection and/or assembly of data; $\mathbf{C}$ - data analysis and interpretation;

$\mathbf{D}$ - writing the article; $\mathbf{E}$ - critical revision of the article; $\mathbf{F}$ - final approval of article; $\mathbf{G}$ - other

\begin{abstract}
Nowadays NSAIDs are the most frequently used groups of drugs, especially because of their availability. Their consumption is high among older people, who are much more sensitive to the side effects, and who are often also taking other drugs which can interact with them. Moreover, the majority of the older population is suffering from hypertension. This could well explain the commonly encountered experience of drug interaction between NSAIDs and antihypertensive drugs, which is very common in clinical practice. The severity of this drug interaction is classified as class $\mathrm{C}$, with a recommendation to monitor therapy. However, even a minor long-term increase in blood pressure can significantly increase the risk of cardiovascular mortality, while mortality rates can possibly be reduced by sufficiently effective treatment of hypertension. Therefore, in clinical practice, this type of interaction should not be overlooked as a major cause of failure of hypertension treatment in older patients, as well in many cases in general. The present article focusses on the mechanism and the degree of influence on the blood pressure of particular types of antihypertensive agents used in combination with NSAID. Not all groups of antihypertensive drugs are affected to the same degree; some are more affected, and others, such as calcium channel blockers, are not affected at all. Similarly, not every NSAID increases blood pressure. Many studies, some of which are analyzed in this article, present evidence of the degree of the influence NSAIDs have on blood pressure (Adv Clin Exp Med 2014, 23, 6, 993-1000).
\end{abstract}

Key words: antihypertensive drugs, non-steroidal anti-inflammatory drugs, blood pressure, hypertension.

Hypertension is well known as one of the most common cardiovascular diseases. Approximately $690 \mathrm{~m}$ people around the world suffer from hypertension. It is one of the major risk factors causing arteriosclerosis, including atherogenic coronary artery disease in the form of ischemic heart disease [1]. Hypertension affects the majority of people over 65 years of age, occurring in up to $60 \%$ of this population [2]. In most cases, it accounts for subsequent organ damage or many other manifestations of cardiovascular diseases [2, 3]. Adequate treatment of hypertension is important especially in older populations, as has been confirmed by the HYVET study [4]. Moreover, older populations often experience pain, both chronic and acute. The use of different analgesics therefore becomes a regular part of their lives. It should therefore be borne in mind that the treatment of hypertension may be significantly influenced by the concomitant use of other therapeutic classes.

The authors of this article focused on clarifying the mechanisms of the influence on blood

* This study was supported by grant SVV 260066 from Charles University in Prague. 
pressure of some combinations of antihypertensive drugs and non-steroidal anti-inflammatory drugs (NSAIDs). A study from 2010 on potential drug interactions in hypertensive patients showed that this interaction is very frequent. The most numerous group (83\%) consisted of interactions with clinical seriousness level C, i.e. with a recommendation to monitor therapy. NSAID and antihypertensive drug interaction have been ranked in the first place in this group [5].

\section{Pain in the Older Population}

As mentioned above, hypertension therapy is of high importance in older patients. A diastolic blood pressure decrease of 5-6 $\mathrm{mm} \mathrm{Hg}$ can lead to a $67 \%$ decrease in the risk of cerebral stroke and a $15 \%$ decrease in the risk of coronary heart disease [6]. Sufficient hypertension therapy can lead to a significant decrease in the risk of cardiovascular events in systolic-diastolic hypertension, as well as in isolated systolic hypertension, which is markedly more frequent in older patients [7]. Systolic blood pressure can be a more effective mortality predictor than diastolic blood pressure [8]. At the same time, pain in older patients is of serious concern, and since the size of this population is increasing, the consumption of analgesics has been constantly increasing. Analgesics are among the drugs most widely used on a long-term basis. Antihypertensive agents and NSAIDs are used at the same time by at least $12-15 \%$ of older patients. The use of analgesics in self-medication of joint and back pain has increased from $28.5 \%$ to $41.5 \%$ in the last 10 years; in systematic target therapy $35.5 \%$ of patients were treated for joint pain and 38.5\% for back pain [9]. NSAIDs are reported to constitute $57.5 \%$ of total pain management by pharmacotherapy, acetaminophen $20.9 \%$ and weak opioids $18.5 \%$. Uncontrolled analgesic usage in by older patients significantly decreases their safety [9]. Unprofessionally treated pain leads to severe problems or adverse effects (e.g., gastrointestinal bleeding; blood pressure elevation; impeded cognitive, renal and hepatic functions; and allergic reactions) [10]. These complications have been reported to occur in more than $25 \%$ of patients using NSAIDs. Out of those patients, $10 \%$ had to be hospitalized due to adverse side effects [9]. Older patients are much more sensitive to the side effects of NSAIDs and should therefore be treated with them carefully. They are also likely to be less cautious in their use of opioid substances in pain management, although fear of addiction to opioid substances in older age is often completely unfounded [11]. The risk of developing an addiction decreases with increased age and is lower in the older population. It ranges from $3 \%$ to $19 \%$, and it is often lower in patients with no previous experience with opioids in their medical history [12].

\section{The Role of Prostaglandins in Blood Pressure Regulation}

Prostaglandins (PGs) play a key role in renal hemodynamics in the kidneys, in ion transport and in renal hormone synthesis. They maintain the balance between hypertensive and antihypertensive mechanisms in the organism (Fig. 1). Thromboxane A2 (TxA2) and prostaglandin H2 (PGH2) are especially significant in hypertensive action. They have vasoconstrictive effects and decrease kidney blood flow. Prostacyclin (PGI2) and prostaglandin E2 (PGE2) counteract these effects, primarily due to their vasodilating effect, which leads to an elevation in blood flow [13]. PGI2 relaxes vascular smooth muscles and supports sodium secretion by lowering glomerular vascular resistance. PGE2 induces vasodilation, but eventually inhibits tubular reabsorption of sodium and chloride ions in the kidneys. It operates as an antagonist of vasopressin (an antidiuretic hormone) in the collecting ducts, increasing water secretion [14-16]. PGs inhibit endothelin 1 synthesis, which increases blood pressure by increasing peripheral vascular resistance [17]. Besides these effects, PGs also influence renin release, which consequently increases the synthesis of angiotensin II (a strong vasoconstrictor) and aldosterone (a hormone regulating water and sodium reabsorption in kidneys) $[13,16]$. NSAIDs suppress PG synthesis and can lead to a decrease in renin release, thereby causing blood pressure to drop in some individuals [13]. However, in individuals who already have low renin levels (e.g. the elderly), the loss of PGI2- and PGE2-mediated vasodilation may not be accompanied by any compensatory reduction in renin-mediated vasoconstriction [16].

The activity of the sympathetic nervous system and renin-angiotensin-aldosterone system is often increased in hypertension. To level the balance between vasoconstrictive and vasodilating mechanisms in the kidneys, increased PG secretion needs to be active. NSAIDs inhibit this compensatory ability, which leads to a predominance of vasoconstrictors and a subsequent increase in blood pressure [18]. The mechanism by which NSAIDs influence blood pressure is still not completely clear, but the most likely option seems to be blockage of cyclooxygenase (COX) and subsequent inhibition of PG synthesis [16]. 


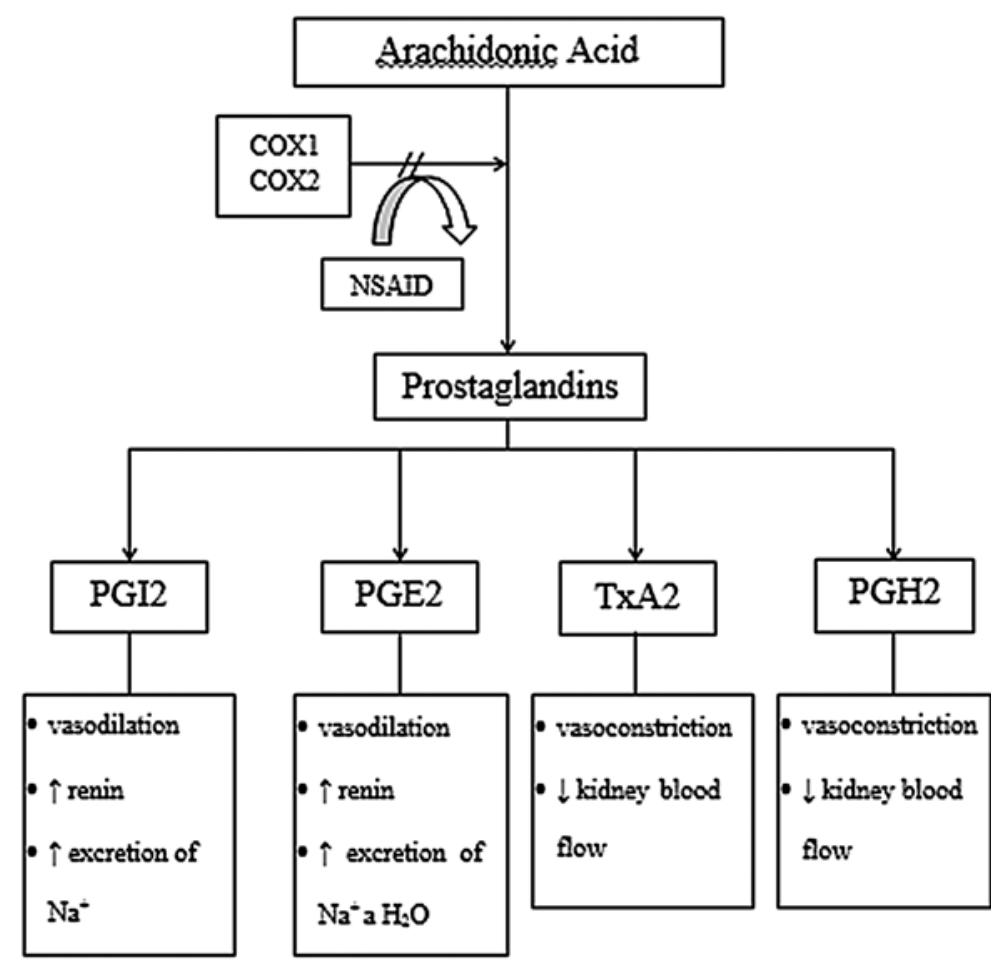

COX 1, COX 2 = cyclooxygenase 1, 2; NSAID = non-steroidal anti-inflammatory drugs; PGI = prostacyclin; $\mathrm{PGE} 2$ = prostaglandin E2; TxA2 = thromboxane $\mathrm{A} 2 ; \mathrm{PGH} 2=$

Fig. 1. Mechanisms of action of non-steroidal anti-inflammatory drugs

\section{The Combination of NSAIDs and Antihypertensive Agents}

Drug interactions between NSAIDs and antihypertensive agents can lead to problems with blood pressure control in patients using both classes of medication at the same time. Blood pressure can increase by up to approximately $5.0 \mathrm{~mm} \mathrm{Hg}$ in this group of older people. However, different classes of antihypertensive drugs are not influenced in the same way. The level of interaction between NSAIDs and antihypertensive drugs depends on how big a role PGs play in the mechanism of action of the antihypertensives $[19,20]$. By influencing PG synthesis, NSAIDs can limit their ability to regulate blood pressure. The probable sites and the relevance of action of NSAIDs on the mechanisms of action of the five main antihypertensive drug groups are presented briefly in Table 1 .

\section{Diuretics}

There are two major classes of diuretics used in the treatment of hypertension: thiazide and loop diuretics. Both classes influence blood pressure by decreasing extracellular water volume and the total peripheral resistance. PG activity in the kidneys supports and increases the effects of diuretics. NSAIDs decrease the effect of diuretics by inhibiting PG synthesis. As a result, the amount of secreted water and salts is lower [21]. This decrease in diuretic effect has been proved in many studies investigating the usage of diuretics and NSAIDs [22-24]. The reduction of diuresis was especially evident in older people [21].

\section{Beta-Blockers}

The mechanism by which beta-blockers (BBs) lower blood pressure is still not completely understood. It has been that some of the following may be involved: a reduction of cardiac output; effects on the central nervous system; inhibition of the reninangiotensin-aldosterone system (RAAS); a reduction in plasma volume, as well of vasomotor tone and peripheral vascular resistance; improvements in vascular compliance; resetting of the baro-receptors, and other models of action [25]. NSAIDs can interfere with some of these mechanisms (Table 1) $[21,26]$. Propranolol has also been found to stimulate PGI 2 synthesis in patients with essential hypertension, and NSAIDs interfere with this 
Table 1. Probable sites and relevance of NSAID activity in the mechanisms of action of antihypertensive drugs

\begin{tabular}{|l|l|l|l|l|l|l|}
\hline $\begin{array}{l}\text { Antihypertensive } \\
\text { classes }\end{array}$ & $\begin{array}{l}\mathrm{Na}^{+} \text {and } \\
\mathrm{H}_{2} \mathrm{O} \\
\text { excretion }\end{array}$ & RAAS & $\begin{array}{l}\text { Brady- } \\
\text { kinin }\end{array}$ & $\begin{array}{l}\text { Decrease of anti- } \\
\text { hypertensive ef- } \\
\text { fect after NSAIDs }\end{array}$ & $\begin{array}{l}\Delta \text { systolic } \\
\text { blood pressure } \\
\text { after NSAIDs }\end{array}$ & Studies \\
\hline Diuretics & $\uparrow$ & - & - & $+/++$ & $\begin{array}{l}6.11^{*} \\
2.1\end{array}$ & $\begin{array}{l}\text { Ishiguro et al [22] } \\
\text { MacDonald et al. [28] }\end{array}$ \\
\hline Beta-blockers & $\uparrow$ & $\downarrow$ & - & $+/++$ & $\begin{array}{l}6.2^{*} \\
2.8\end{array}$ & $\begin{array}{l}\text { Johnson et al. [27] } \\
\text { MacDonald et al. [28] }\end{array}$ \\
\hline ACE inhibitors & $\uparrow$ & $\downarrow$ & $\uparrow$ & +++ & $\begin{array}{l}10.3^{*} \\
6.8^{*} \\
3.7^{*}\end{array}$ & $\begin{array}{l}\text { Morgan and Anderson [35] } \\
\text { Polonia et al. [34] } \\
\text { MacDonald et al. [28] } \\
\text { Conlin et al. [29] } \\
\text { Morgan and Anderson [36] }\end{array}$ \\
\hline $\begin{array}{l}\text { Angiotensin II } \\
\text { blockers }\end{array}$ & $\uparrow$ & & & & & $4.6^{*}$ \\
\hline $\begin{array}{l}\text { Calcium channel } \\
\text { blockers }\end{array}$ & $\uparrow$ & $\uparrow$ & $\uparrow$ & $++/+++$ & $\begin{array}{l}4.6^{*} \\
3.8^{*}\end{array}$ & $\begin{array}{l}\text { MacDonald et al. [28] } \\
\text { Conlin et al. [29] }\end{array}$ \\
\hline
\end{tabular}

RAAS - renin-angiotensin-aldosterone system, ACE - angiotensin converting enzyme; + ++ +++ -: measure of antihypertensive effect; ${ }^{*}$ significant value.

process in such a way that even the PGI 2 synthesis induced by propranolol will not prevent blockage of the BB antihypertensive effect [21]. According to a meta-analysis carried out by Johnson et al., NSAIDs block the antihypertensive effect of BBs more significantly than diuretics do [27].

\section{Angiotensin-Converting- -Enzyme Inhibitors}

Angiotensin-converting-enzyme (ACE) inhibitors induce vasodilation and decrease blood pressure by inhibiting angiotensin II and aldosterone production. If ACE is blocked by ACE inhibitors, bradykinin is not inactivated, which leads to further vasodilation and blood pressure decrease. Bradykinin enhances the antihypertensive effect of ACE inhibitors. It also stimulates the release of PGs, which play a key role in vasodilation. The decrease in blood pressure stimulated by bradykinin is crucial to the full effect of ACE inhibitors. NSAIDs block vasodilation by inhibiting PGs, thereby significantly lowering the antihypertensive effect of ACE inhibitors. This effect is more pronounced in hypertensive patients with lower renin levels, because the decrease in blood pressure caused by ACE inhibitors is induced primarily by influencing bradykinin $[21,26]$. Because of this, the effect of ACE inhibitors is to a large extent dependent on PGs synthesis, which is why the influence of ACE inhibitors on blood pressure, when administered in combination with NSAIDs, is very similar to the effect of angiotensin II blockers $[28,29]$.

\section{Angiotensin II Blockers}

Angiotensin II blockers decrease blood pressure by blocking the receptor for angiotensin II type 1 (AT1). This mechanism leads to increased vasodilation and salt reabsorption [21], and to decrease of aldosterone production [30]. It is important to note that there is no blockage of AT2 receptors in angiotensin II blockers. This fact probably plays an essential role in blood pressure regulation by causing a release of bradykinin and nitrous oxide (NO), which in turn also induces vasodilation. PG inhibition can inhibit the functioning of angiotensin II blockers [31], which are affected by NSAIDs at the same high level as ACE inhibitors are [28].

\section{Calcium Channel Blockers (CCBs)}

CCBs, which are used in hypertension therapy, do not significantly interact with NSAIDs [19]. Their antihypertensive effect is not dependent on the action of PGs [32]. CCBs specifically inhibit $\mathrm{Ca}^{2+}$ ion penetration through L-type voltage-dependent calcium channels into vascular smooth 
muscle cells, contractile and conducting myocardium cells. After administration, intracellular calcium concentrations decrease and the resulting effect is a reduction in myocardial contractility and excitability, which reduces the myocardial metabolic demand of oxygen. The antihypertensive effect is achieved through dilatation of arterioles and a consequent reduction in blood pressure [33].

\section{The Influence of NSAIDs on Blood Pressure Level}

NSAIDs can be classified on the basis of their selectivity to cyclooxygenase (COX). Non-selective NSAIDs inhibit both COX 1 and COX 2 isoenzymes, while selective COX 2 NSAIDs only inhibit isoenzyme COX 2 [17]. As mentioned above, not all NSAIDs influence blood pressure to an equal extent; they can be divided into one group with a stronger influence on blood pressure and another group with little or no influence. It has been assumed that the pro-hypertensive effect of NSAIDs is associated with sodium and fluid retention [34]. Indomethacin, naproxen and piroxicam increase blood pressure more efficiently in comparison with sulindac or aspirin $[19,32]$. Sulindac has been shown to preserve the synthesis of PGs, which could explain why it has a lesser effect on blood pressure than indomethacin, piroxicam and naproxen, with which it has been compared [6].

In a prospective study, Pavličevič et al. observed 88 patients over 55 years old who were treated with antihypertensive agents. In the control group there were 17 women and 22 men, aged $68.5 \pm 6.7$ years. The patients were given either a combination of lisinopril/hydrochlorothiazide or amlodipine. In the intervention group, the patients were divided into 4 subgroups: $30 \%$ of the patients used lisinopril/hydrochlorothiazide with ibuprofen; $28.6 \%$ used lisinopril/hydrochlorothiazide with piroxicam; $22.4 \%$ used amlodipine with ibuprofen; and $18.4 \%$ used amlodipine with piroxicam. The mean age in the intervention group was $69.8 \pm 6.9$ years. In the lisinopril/hydrochlorothiazide subgroup with piroxicam, the average systolic blood pressure increased by $14.1 \mathrm{~mm} \mathrm{Hg}$, and in the lisinopril/hydrochlorothiazide subgroup with ibuprofen, the average systolic blood pressure increased by $11.2 \mathrm{~mm} \mathrm{Hg}$. These results show that ibuprofen and piroxicam significantly elevated blood pressure in the group of patients with lisinopril/hydrochlorothiazide in comparison with the control group, in which the blood pressure decreased by $0.1 \mathrm{~mm} \mathrm{Hg}$. The blood pressure elevation in the amlodipine group was very small (with piroxicam $1.7 \mathrm{~mm} \mathrm{Hg}$; with ibuprofen $2.4 \mathrm{~mm} \mathrm{Hg}$ ) compared to the control group $(0.2 \mathrm{~mm} \mathrm{Hg})$, and no significant correlation was confirmed [19].

Wilson and Poulter [16] cited three studies in their review comparing the influence of indomethacin on the ACE inhibitor enalapril and on calcium channel blockers such as nifedipine [34], felodipine [35] and amlodipine [36]. The results of these studies were very similar. In the study listed first, by Polonia et al. [34], eighteen randomized patients were taking enalapril/indomethacin or nifedipine/indomethacin over a period of one week. In the enalapril/indomethacin group, the increase in blood pressure was $6.8 \mathrm{~mm} \mathrm{Hg}$, while in the nifedipine/indomethacin group it was only $0.3 \mathrm{~mm} \mathrm{Hg}$. In the second study, by Morgan and Anderson [35], 12 patients were randomized into a felodipine group and 15 patients into an enalapril group. After 4 weeks of $100 \mathrm{mg}$ of indomethacin, there was a higher blood pressure increase in the enalapril group $(10.3 \mathrm{~mm} \mathrm{Hg} ; \mathrm{p}<0.01)$ than in the felodipine group (1.3 $\mathrm{mm} \mathrm{Hg})$. The third study, also by Morgan and Anderson [36], involved 24 patients on enalapril and 26 patients on amlodipine randomized in the study. The patients in both groups took $100 \mathrm{mg}$ of indomethacin for two weeks. A significant increase in blood pressure (11.7 mm Hg; $\mathrm{p}=0.002$ ) was noted in the enalapril group, whereas no significant increase (1.1 $\mathrm{mm} \mathrm{Hg}$ ) was noted in the amlodipine group. Significant blood pressure elevation was found in all the study groups with enalapril/indomethacin, compared to all the groups with CCBs/indomethacin, where blood pressure elevation was only minimal.

The group of selective COX 2 NSAIDs has been compared with the group of non-selective NSAIDs. According to a meta-analysis in 2005 [37], selective inhibitors of COX-2 (coxibs) caused a bit higher blood pressure elevation compared to non-selective NSAIDs. In the meta-analysis, rofecoxib with a placebo, rofecoxib with a non-selective NSAID, celecoxib with a placebo, celecoxib with a non-selective NSAID and rofecoxib with celecoxib were compared. The increase in blood pressure was $5.66 \mathrm{~mm} \mathrm{Hg}, 3.32 \mathrm{~mm} \mathrm{Hg}$, $2.60 \mathrm{~mm} \mathrm{Hg}, 0.14 \mathrm{~mm} \mathrm{Hg}$ and $2.83 \mathrm{~mm} \mathrm{Hg}$, respectively. This confirms the presumption that various levels of blood pressure elevation is a property of all NSAIDs.

The meta-analysis by Pope et al. [38] included 54 studies that involved 1213 hypertonic patients (92\%) out of 1324 respondents. The influence of NSAIDs on blood pressure was only proved in patients suffering from hypertension. Their blood pressure increased by $3.32 \mathrm{~mm} \mathrm{Hg}$ on average, while in normotensive patients the blood pressure elevation was $1.12 \mathrm{~mm} \mathrm{Hg}$. In hypertensive patients 
with natural salt intake, the average arterial tension increased by $4.77 \mathrm{~mm} \mathrm{Hg}$ after indomethacin therapy, $6.10 \mathrm{~mm} \mathrm{Hg}$ after naproxen therapy and $2.86 \mathrm{~mm} \mathrm{Hg}$ after piroxicam therapy. Blood pressure decreased by $0.23 \mathrm{~mm} \mathrm{Hg}$ in patients using a placebo, and a similar decrease was noted in the group using ibuprofen. Sulindac increased blood pressure by $2.2 \mathrm{~mm}$, and acetylsalicylic acid increased it by $0.61 \mathrm{~mm} \mathrm{Hg}$. Patients with lower salt intake suffered from blood pressure elevation only after indomethacin and naproxen (more than $3.5 \mathrm{~mm} \mathrm{Hg}$ ); piroxicam increased blood pressure by only $0.45 \mathrm{~mm} \mathrm{Hg}$ on average. Other substances, like ibuprofen, placebo, sulindac and acetylsalicylic acid, showed an average arterial tension decrease. Pressure changes in the indomethacin group were significantly higher than in the sulindac group ( $\mathrm{p}<0.002)$, and they also differed from acetylsalicylic acid and placebo $(\mathrm{p}<0.05)$ groups. Naproxen influenced blood pressure distinctly less when the patients' salt intake was modified (from 6.1 to $3.7 \mathrm{~mm} \mathrm{Hg}$ ), but despite that it still noticeably differed from ibuprofen, acetylsalicylic acid and sulindac ( $\mathrm{p} \leq 0.03)$.

In a meta-analysis by Johnson et al. [27], data from 50 randomized studies with 771 patients were processed. The findings observed in this study mirror those of the study outlined in the previous paragraph. The average blood pressure was increased by $5 \mathrm{~mm} \mathrm{Hg}$ in patients using NSAIDs. Indomethacin and piroxicam led to marked increases; however, only piroxicam increased blood pressure to a statistically significant degree $(6.2 \mathrm{~mm} \mathrm{Hg})$. Ibuprofen, tiaprofenic acid, diclofenac, naproxen, flurbiprofen, sulindac and acetylsalicylic acid let to only minor increases in blood pressure. Blood pressure elevation appeared in hypertonic patients only. The effect of blood pressure elevation was more significant in normotensive patients using antihypertensive medications (hypertonic patients with sufficiently corrected hypertension) in comparison with hypertensive people without any antihypertensive treatment or with healthy normotensive people $(5.4 \mathrm{~mm} \mathrm{Hg} v$ s. $2.5 \mathrm{~mm} \mathrm{Hg}$ and $1.1 \mathrm{~mm} \mathrm{Hg}$, respectively).
The effect of celecoxib, rofecoxib and naproxen during 24-hour blood pressure monitoring in patients with osteoarthrosis, DM2 and hypertension, all of whom were treated with antihypertensive drugs, was evaluated in the CRESCENT study [39]. This double-blind randomized study included 404 patients who used $200 \mathrm{mg} /$ day of celecoxib or $25 \mathrm{mg} /$ day of rofecoxib or $500 \mathrm{mg}$ of naproxen twice a day for 12 weeks. The highest blood pressure increase was recorded in the rofecoxib group (3.7 $\mathrm{mm} \mathrm{Hg}$ ), followed by the celecoxib group ( $0.3 \mathrm{~mm} \mathrm{Hg}$ ). Naproxen increased the blood pressure by $3.6 \mathrm{~mm} \mathrm{Hg}$.

Most of these studies did not directly target geriatric patients. However, a project by Johnson et al. [40] focused precisely on this group: 2805 non-institutionalized patients, all over 65 years old, took part. The study observed the use of NSAIDs and subsequent blood pressure values. The frequency of NSAID usage was divided into groups according to age, gender, blood pressure and arthritis history. Of the total study population, $26 \%$ noted use of NSAIDs. In this group, $12 \%$ of the subjects were using NSAIDs and antihypertensive medications concurrently. In patients using NSAIDs, hypertension occurrence was up to 1.4 times more frequent than in those who did not use them. It was found that in almost $29 \%$ of the subjects who were taking NSAIDs and antihypertensive drugs simultaneously, the hypertension could be attributed to the use of NSAIDs.

The authors concluded that when prescribing NSAIDs, physicians should not forget that their joint use with antihypertensive therapy leads to worsened blood pressure control. Both hypertension occurrence and NSAID use increase with age, and older population are likely to be more predisposed to blood pressure elevation owing to NSAID use. Potentially, this increase can be very serious because even a relatively slight elevation in blood pressure (less than $5 \mathrm{~mm} \mathrm{Hg}$ ) can contribute to an increase in the occurrence of infarctions or the risk of heart failure [21]. In cases where NSAID administration is necessary, it is highly recommended to choose substances with a lower potential of influencing the patient's blood pressure [6].

\section{References}

[1] Grundmann M, Kacírová I: Combination therapy for hypertension. Ambulantná terapia 2007, 5, 106-110.

[2] Cífková R: Hypertension in the elderly. Kap Kardiol 2012, 4, 9-13.

[3] Juszczyk Z: Systolic hypertension in older persons - Controversies and indications for treatment. Adv Clin Exp Med 2006, 15, 521-526.

[4] Beckett NS, Peters R, Fletcher AE, Staessen JA, Liu L, Dumitrascu D, Stoyanovsky V, Antikainen RL, Nikitin Y, Anderson C, Belhani A, Forette F, Rajkumar C, Thijs L, Banya W, Bulpitt CJ, HYVET Study Group: Treatment of hypertension in patients 80 years of age or older. N Engl J Med 2008, 358, 1887-1898.

[5] Bacic-Vrca V, Marusic S, Erdeljic V, Falamic S, Gojo-Tomic N, Rahelic D: The incidence of potential drug-drug interactions in elderly patients with arterial hypertension. Pharm World Sci 2010, 32, 815-821. 
[6] Johnson AG: NSAIDs and blood pressure. Clinical importance for older patients. Drugs Aging 1998, 12, 17-27.

[7] Frishman WH: Effects of Nonsteroidal Anti-Inflammatory Drug Therapy on Blood pressure and Peripheral Edema. Am J Cardiol 2002, 89, 18-25.

[8] Halawa B: Unresolved problems in hypertension treatment. Adv Clin Exp Med 2001, 10, 115-119.

[9] Vondráčková D: Treatment of pain in elderly patients. Čes Ger Rev 2004, 1, 28-36.

[10] Armstrong EP, Malone DC: The impact of nonsteroidal anti-inflammatory drugs on blood pressure, with an emphasis on newer agents. Clin Ther 2003, 25, 1-18.

[11] Vondráčková D: Treatment of nonmalignant pain in geriatric patients opioids. Čes Ger Rev 2008, 6, $103-108$.

[12] Auret K, Schug SA: Underutilisation of opioids in elderly patients with chronic pain: approaches to correcting the problem. Drugs Aging 2005, 22, 641-654.

[13] Nasjletti A: Arthur C. Corcoran Memorial Lecture. The role of eicosanoids in angiotensin-dependent hypertension. Hypertension 1998, 31, 194-200.

[14] Schlondorff D: Renal complications of nonsteroidal anti-inflammatory drugs. Kidney Int 1993, 44, $643-653$.

[15] Smith MC, Dunn MJ: The role of prostaglandins in human hypertension. Am J Kidney Dis 1985, 5, 32-39.

[16] Wilson SL, Poulter NR: The effect of non-steroidal anti-inflammatory drugs and other commonly used nonnarcotic analgesics on blood pressure level in adults. J Hypertens 2006, 24, 1457-1469.

[17] Gaziano JM: Nonnarcotic Analgesics and Hypertension. Am J Cardiol 2006, 97, 10-16.

[18] Zadražil J: Nonsteroidal antiinflammatory drugs and the kidney. Vnitř Lék 2006, 52, 7-8.

[19] Pavlicević I, Kuzmanić M, Rumboldt M, Rumboldt Z: Interaction between antihypertensives and NSAIDs in primary care: a controlled trial. Can J Clin Pharmacol 2008, 15, 372-382.

[20] Hersh EV, Pinto A, Moore PA: Adverse drug interactions involving common prescription and over-the-counter analgesic agents. Clin Ther 2007, 29, 2477-2497.

[21] Ruoff GE: The impact of nonsteroidal anti-inflammatory drugs on hypertension: alternative analgesics for patients at risk. Clin Ther 1998, 20, 376-387.

[22] Ishiguro C, Fujita T, Omori T, Fujii Y, Mayama T, Sato T: Assessing the effects of non-steroidal anti-inflammatory drugs on antihypertensive drug therapy using post-marketing surveillance database. J Epidemiol 2008, 18, 119-124.

[23] Favre L, Glasson P, Riondel A, Vallotton MB: Interaction of diuretics and non-steroidal anti-inflammatory drugs in man. Clin Sci (Lond) 1983, 64, 407-415.

[24] Herchuelz A, Derenne F, Deger F, Juvent M, Van Ganse E, Staroukine M, Verniory A, Boeynaems JM, Douchamps J: Interaction between nonsteroidal anti-inflammatory drugs and loop diuretics: modulation by sodium balance. J Pharmacol Exp Ther 1989, 248, 1175-1181.

[25] Mason RP, Giles TD, Sowers JR: Evolving mechanisms of action of beta blockers: focus on nebivolol. J Cardiovasc Pharmacol 2009, 54, 123-128.

[26] Whelton A: Nephrotoxicity of nonsteroidal anti-inflammatory drugs: physiologic foundations and clinical implications. Am J Med 1999, 106, 13-24.

[27] Johnson AG, Nguyen TV, Day RO: Do nonsteroidal anti-inflammatory drugs affect blood pressure? A metaanalysis. Ann Intern Med 1994, 121, 289-300.

[28] MacDonald TM, Richard D, Lheritier K, Krammer G: The effects of lumiracoxib 100 mg once daily vs. ibuprofen $600 \mathrm{mg}$ three times daily on the blood pressure profiles of hypertensive osteoarthritis patients taking different classes of antihypertensive agents. Int J Clin Pract 2010, 64, 746-755.

[29] Conlin PR, Moore TJ, Swartz SL, Barr E, Gazdick L, Fletcher C, DeLucca P, Demopoulos L: Effect of indomethacin on blood pressure lowering by captopril and losartan in hypertensive patients. Hypertension 2000, 36, 461-465.

[30] Oral I: Medicaments reducing the effectiveness of antihypertensive drugs. Klin Farmakol Farm 2004, 18, $22-25$.

[31] Schmieder RE: Mechanisms for the clinical benefits of angiotensin II receptor blockers. Am J Hypertens 2005, 18, $720-730$.

[32] Salort-Llorca C, Mínguez-Serra MP, Silvestre-Donat FJ: Interactions between ibuprofen and antihypertensive drugs: incidence and clinical relevance in dental practice. Med Oral Patol Oral Cir Bucal 2008, 13, 717-721.

[33] Perlík F, Lincová D, Fendrich Z: Substances affecting the cardiovascular and renal systems. In: Basic and Applied Pharmacology. Second, supplemented and revised edition. Eds.: Lincová D, Farghali H, Galén Prague 2007, $2^{\text {nd }}$ ed., 219-269.

[34] Polónia J, Boaventura I, Gama G, Camões I, Bernardo F, Andrade P, Nunes JP, Brandão F, Cerqueira-Gomes M: Influence of non-steroidal anti-inflammatory drugs on renal function and $24 \mathrm{~h}$ ambulatory blood pressure-reducing effects of enalapril and nifedipine gastrointestinal therapeutic system in hypertensive patients. J Hypertens 1995, 13, 925-931.

[35] Morgan T, Anderson A: Interaction of indomethacin with felodipine and enalapril. J Hypertens 1993, 11, 338-339.

[36] Morgan T, Anderson A: The effect of nonsteroidal anti-inflammatory drugs on blood pressure in patients treated with different antihypertensive drugs. J Clin Hypertens (Greenwich) 2003, 5, 53-57.

[37] Aw TJ, Haas SJ, Liew D, Krum H: Meta-analysis of cyclooxygenase-2 inhibitors and their effects on blood pressure. Arch Intern Med 2005, 165, 490-496.

[38] Pope JE, Anderson JJ, Felson DT: A meta-analysis of the effects of nonsteroidal anti-inflammatory drugs on blood pressure. Arch Intern Med 1993, 153, 477-484. 
[39] Sowers JR, White WB, Pitt B, Whelton A, Simon LS, Winer N, Kivitz A, van Ingen H, Brabant T, Fort JG, Celecoxib Rofecoxib Efficacy and Safety in Comorbidities Evaluation Trial (CRESCENT) Investigators: The Effects of cyclooxygenase-2 inhibitors and nonsteroidal anti-inflammatory therapy on 24-hour blood pressure in patients with hypertension, osteoarthritis, and type 2 diabetes mellitus. Arch Intern Med 2005, 165, 161-168.

[40] Johnson AG, Simons LA, Simons J, Friedlander Y, McCallum J: Non-steroidal anti-inflammatory drugs and hypertension in the elderly: a community-based cross-sectional study. Br J Clin Pharmacol 1993, 35, 455-459.

\section{Address for correspondence:}

Stanislava Kalafutova

Faculty of Pharmacy in Hradec Kralove

Department of Social and Clinical Pharmacy

Heyrovskeho 1203

50005 Hradec Kralove

The Czech Republic

Tel.: +420 495067486

E-mail: stanislava.kalafutova@faf.cuni.cz

Conflict of interest: None declared

Received: 21.06 .2013

Revised: 5.03.2014

Accepted: 15.10.2014 